\title{
Advanced glycation end products and risk of general and abdominal obesity in Iranian adults: Tehran lipid and glucose study
}

\author{
Parvin Mirmiran ${ }^{1}$, Hoda Hadavi ${ }^{1}$, Azadeh Mottaghi*2, Fereidoun Azizi ${ }^{3}$
}

Received: 1 Aug 2017

Published: 25 March 2019

\section{Abstract}

Background: Advanced glycation end products (AGEs) are a heterogeneous group of macromolecules that are formed by the nonenzymatic glycation of proteins, lipids, and nucleic acids. A number of food preparation methods can increase AGEs content. The aim of the present study is to assess the relationship between dietary consumption of AGEs and the risk of obesity and central obesity.

Methods: This study was conducted within the framework of the Tehran Lipid and Glucose Study (TLGS) on 4245 subjects who participated in its fifth phase (2011 to 2014). Dietary data were collected using a validated semi-quantitative food frequency questionnaire (FFQ). Participants' characteristics, anthropometric measures, and blood samples were also obtained by trained staff. Multivariable linear regression and Logistic regression was conducted using SPSS (Version 20; Chicago, IL), and P values $<0.05$ were considered significant.

Results: Our results show that abdominal obesity was increased with higher intakes of dietary AGEs, an association, which remained significant after adjustment for potential confounders $(\mathrm{OR}=1.56$ and $95 \% \mathrm{CI}, 1.16$ to 2.84). The relationship between abdominal obesity and dietary AGEs (dAGEs) intake was found to be independent of energy and macronutrient intake. We also found a relationship between consumption of dAGEs and a few anthropometric measurements, such that a significant positive correlation was observed between BMI, WC, BAI and higher quartiles of dAGEs intake, with the correlation being stronger for BAI $(\beta=0.24(0.10$ $0.39)$ ).

Conclusion: Our study emphasizes that higher intake of dAGEs does increase the chance of abdominal obesity, and dAGEs might be a link between modern diets and obesity.

Keywords: General obesity, Abdominal obesity, Advanced glycation end products

Conflicts of Interest: None declared

Funding: None

*This work has been published under CC BY-NC-SA 1.0 license.

Copyright $\subseteq$ Iran University of Medical Sciences

Cite this article as: Mirmiran P, Hadavi H, Mottaghi A, Azizi F. Advanced glycation end products and risk of general and abdominal obesity in Iranian adults: Tehran lipid and glucose study. Med J Islam Repub Iran. 2019 (25 March);33:21. https://doi.org/10.47176/mjiri.33.21

\section{Introduction}

Obesity is a major concern of most, if not all, governments who now readily accept its complexity and major public health impact (1). It is recognized as a health hazard that has reached epidemic proportions in affluent and emerging economies (2), and according to the WHO report, obesity has become a worldwide epidemic (3). In 2008, the overall prevalence of obesity in the Middle East region was estimated to be $24.5 \%$ (4), indicating that 1 in every 4 individuals living in the Middle East is obese. In a large national survey, the national estimate of overweight

\footnotetext{
Corresponding author:Dr Azadeh Mottaghi, mottaghi.a@iums.ac.ir

1. Nutrition and Endocrine Research Center, Research Institute of Endocrine Sciences, Shahid Beheshti University of Medical Sciences, Tehran, Iran

2. Research Center for Prevention of Cardiovascular Diseases, Institute of Endocrinology \& Metabolism, Iran University of Medical Sciences, Tehran, Iran

3. Endocrine Research Center, Research Institute for Endocrine Sciences, Shahid Beheshti University of Medical Sciences, Tehran, Iran
}

and obesity altogether was calculated to be $42.8 \%$ in Iranian adults; Their results also suggest that our population can expect to see a very high rate of chronic diseases, in the near future as a consequence of the high prevalence of overweight, particularly of abdominal obesity (5).

Advanced glycation end products (AGEs) are a heterogeneous group of macromolecules that are formed by the non-enzymatic glycation of proteins, lipids, and nucleic acids. AGEs are formed when food is processed at elevated temperatures, such as during grilling, broiling, roasting,

$\uparrow$ What is "already known" in this topic:

There is a large body of evidence on a correlation between fat mass and advanced glycation end products.

$\rightarrow$ What this article adds:

Association between fat mass distribution (abdominal and general) was assessed in the present article. 
searing, and frying and also in the production of certain foods namely pasteurized dairy products, cheeses, sausages, and processed meats $(6,7)$. Dietary advanced glycation end products (dAGEs), which have been implicated in the development of diabetic and other vascular diseases, are known to contribute to increased oxygen-free radicals and oxidant stress and elevated inflammation in the system (79). AGEs have also been independently related to increased risk of a number of chronic diseases, such as insulin resistance and diabetes (10-13). Angoorani et al. observed that higher intake of AGEs was associated with higher risk of two components of MetS including abdominal obesity and hypertriglyceridemia in Iranian adults (14).

AGEs contribute to a variety of microvascular and macrovascular complications through the formation of cross-links between molecules in the basement membrane of the extracellular matrix and by engaging the receptor for advanced glycation end products (RAGE). The presence and accumulation of AGEs in many different cell types affect the extracellular and intracellular structure and function (15). Results of a recent meta-analysis showed that diets low in AGEs might be an effective strategy for improving cardiometabolic profiles in individuals with and without type 2 diabetes (16).

Although a relationship between dAGEs and increased adiposity seems plausible, the impact of consuming dAGEs on the risk of obesity and visceral obesity is unclear. The aim of the present study is to assess the relationship between dietary consumption of AGEs and the risk of obesity and central obesity.

\section{Methods}

\section{Study population}

This study was conducted within the framework of the Tehran Lipid and Glucose Study (TLGS). In brief, TLGS is a community-based prospective study being conducted to investigate non-communicable diseases, in a representative sample of residents, aged $\geq 3 \mathrm{y}$, from district 13 of Tehran, the capital city of Iran. The first phase of the TLGS began in March 1999 and data collection, at threeyear intervals, is ongoing (17).

For the current study, 9602 men and women aged 19 to 70 years, who participated in the fifth phase of TLGS (2011 to 2014) were recruited. We excluded participants if they lacked information on sex and anthropometric measurements $(n=2004)$, if they were underweight $(n=68)$, if they had no dietary intake information $(n=3083)$, if they were under- or over-reporters of dietary intakes $(<800$ $\mathrm{kcal} /$ day or $>4,200 \mathrm{kcal} /$ day, respectively; $\mathrm{n}=202$ ). After exclusions, the final analysis was conducted on data of 4245 participants (Fig. 1).

All participants signed informed consents, and the study protocol was approved by the research council of the Research Institute for Endocrine Sciences (RIES), Shahid Beheshti University of Medical Sciences.

\section{Dietary assessment}

Dietary data were collected using a validated semiquantitative food frequency questionnaire (FFQ) with 147 food items, developed for the TLGS. Trained dietitians completed the FFQ during face-to-face interviews, asking participants to report the frequency of consumption of

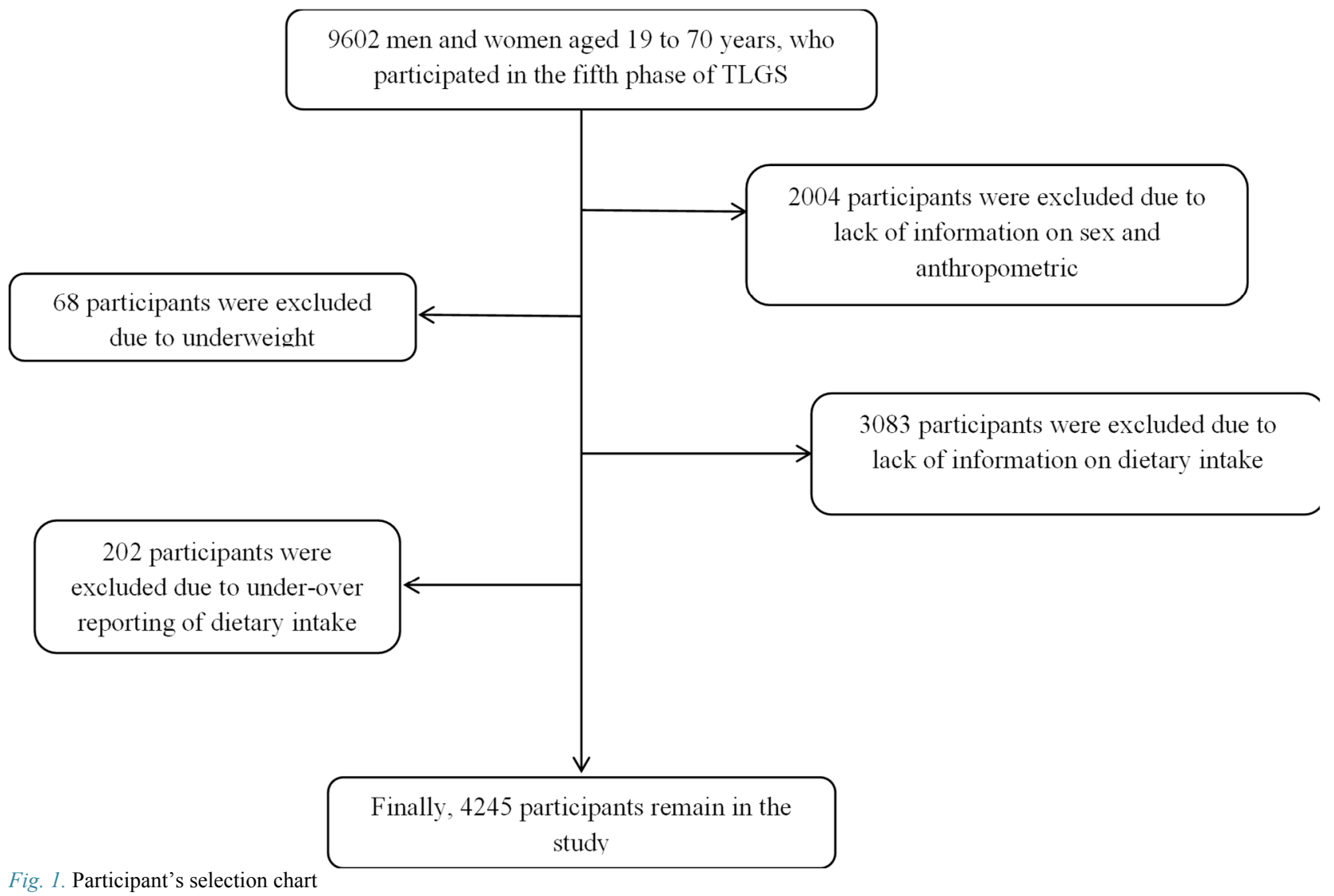

Fig. 1. Participant's selection chart 
each food item, during the past year on a daily, weekly or monthly basis. These reports were converted to daily intakes. Analysis of dietary intake was done by Nutritionist IV. The validity and reliability of the FFQ for food group intakes were assessed and were acceptable (18). In order to calculate total dietary AGEs intake, we used the published food AGEs database $(7,19)$ for 549 commonly consumed food items for the Northeastern American multi-ethnic urban population which was measured using a validated immunoassay method, because the Iranian Food Composition Table (FCT) has no data on AGEs content of foods. We determine the AGEs values kilo-Unit $(\mathrm{kU})$ in $100 \mathrm{~g}$ solid food or $100 \mathrm{ml}$ liquid for 147 food items evaluated in the FFQ of the fifth phase of TLGS. The FFQ included questions on the frequency of consumption and usual portion size of the food item. We calculated the total AGEs consumption per day for each participant and for data analysis; portion sizes of consumed food items reported in household measures were converted to grams, and their intakes were categorized using quartile cutoffs $(<4799,4799$ to 6324,6324 to 8461 , $>8461 \mathrm{kU} /$ day). The amount of AGEs consumption was adjusted for daily energy intake; AGEs values for some Iranian specific food items, e.g. some kinds of bread and cookies were estimated from similar food items for which the AGEs value was available; since AGEs value was not available for all fruits or vegetables, we used the mean values of fruits or vegetables available to substitute for the others (20). Finally, we obtained the AGEs values for 108 out of 147 food items in the FFQ of the fourth phase of TLGS; 39 items, which had no similar items in the main list, were set as missing.

\section{Anthropometrics and lifestyle measurements}

Trained interviewers collected the participants' characteristics using a questionnaire. Information on age (years), educational level (illiterate, primary education and academic education), smoking status (yes/no), and physical activity level (METhr/wk) were also assessed. Participants who smoked daily or occasionally were considered current smokers, and those who had never smoked or those who stopped smoking were considered non-smokers. For assessing of physical activity level, we used the Persian translated Modifiable Activity Questionnaire (MAQ) (21). Physical activity levels were expressed as metabolic equivalent hours per week (METs h/wk). High reliability and relatively moderate validity were reported for the Persian translated MAQ in Tehranian adults (22).

Weight was measured while the subjects were minimally clothed without shoes, using digital scales and recorded to the nearest $100 \mathrm{~g}$. Height was measured in a standing position, without shoes, using tape meter while shoulders were in a normal state. Body mass index (BMI) was calculated as weight in kilogram divided by height in meters squared.

Waist circumference was measured to the nearest 0.1 $\mathrm{cm}$ (at anatomical landmarks), at the widest portion, over light clothing, using a soft, tape meter, without any pressure to the body. Body adiposity index was calculated as (hip (cm)/height (m) ${ }^{1.5}$ )-18) (23). Body mass index $\geq 30$ $\mathrm{kg} / \mathrm{m} 2$ was classified as general obesity and waist circumference $\geq 95 \mathrm{~cm}$, for both sexes, was classified as abdominal obesity (24).

\section{Statistical analysis}

All statistical analysis was conducted using SPSS (Version 20; Chicago, IL), and $\mathrm{P}$ values $<0.05$ were considered significant. Dietary AGEs were divided into quartiles, and participant characteristics were compared across quartile categories of AGEs intake, using one-way analysis of variance (ANOVA), or the Chi-square test. Dietary intakes of participants were compared across quartiles of AGEs intakes, using one-way ANOVA or Kruskal-Wallis test. The association between body mass index, waist circumference, and body adiposity index as continuous variables and quartiles of AGEs intakes were determined using multiple linear regression models with adjustment for age, sex, physical activity, smoking status, education status and energy intake. Data are presented as $\beta$ regression and $95 \%$ confidence interval. The odds ratio (OR) of general and abdominal obesity in each quartile of AGEs intake was determined using the binary logistic regression models. Logistic regression models included a dichotomous outcome (obesity (yes or no) or abdominal obesity (yes or no)) and quartiles of AGEs intakes as the main predictor of interest, adjusted for age, sex, physical activity, smoking status, education status, and energy intake. Because total energy intake and macronutrients could be in the pathway between AGEs intakes and obesity risk, energy intake was included in an additional model. Data are presented as OR with $95 \%$ confidence interval (CI).

\section{Results}

The mean \pm SD age of the participants was $44.9 \pm 11.7$ years, $58 \%$ of participants were women and the mean BMI was $28.1 \pm 4.9 \mathrm{~kg} / \mathrm{m}^{2}$. Mean dietary intake of AGEs was $7043 \pm 3426 \mathrm{kU} / \mathrm{day}(7063$ and $7028 \mathrm{kU} / \mathrm{d}$, in men and women, respectively). The mean consumption of AGEs in the first to fourth quartile category was 4832, 4832-6329, $6329-8466$ and $8466 \mathrm{kU} /$ day, respectively. Prevalence of general obesity in the overall population was $29 \%$ and in case of abdominal obesity was $45 \%$. The distribution of general obesity across quartile of AGEs intake were statistically significant $(\mathrm{p}=0.015)$.

Characteristics of the study participants across quartile categories of AGEs are shown in Table 1.

Subjects in the highest, compared to the lowest quartile category of AGEs intake were more likely to be younger (42.7 years vs. 46.7 years, $\mathrm{p}<0.001$ ), more likely to be smokers $(22 \%$ vs. $30 \%, p=0.024)$ and were more active (2003 Met-hr/week vs. 2183 Met-hr/week, p= 0.554). Higher intakes of AGEs were accompanied with higher education level $(\mathrm{p}<0.001)$, higher BMI $(0.032)$ and higher waist circumference $(\mathrm{p}=0.018)$.

Mean dietary intakes of participants by categories of AGEs intake are illustrated in Table 2. Participants with highest intake of AGEs had higher calorie intake, compared to those in the lowest quartile of AGEs intake (1754 $\mathrm{kcal} /$ day vs. $2853 \mathrm{kcal} / \mathrm{day}, \mathrm{p}<0.001)$. Moreover, fat and 
Table 1. Characteristics of participants by quartile categories of dietary AGEs intake: Tehran Lipid and Glucose Study

\begin{tabular}{|c|c|c|c|c|c|}
\hline & \multicolumn{5}{|c|}{$(n=4080)$} \\
\hline & Q1 & Q2 & Q3 & Q4 & $\mathrm{p}$ \\
\hline & $\mathrm{n}=1019$ & $\mathrm{n}=1021$ & $\mathrm{n}=1021$ & $\mathrm{n}=1019$ & \\
\hline \multicolumn{6}{|l|}{ Dietary AGEs intake } \\
\hline Range & $<4832$ & $4832-6329$ & $6329-8466$ & $>8466$ & \\
\hline Mean & $3678 \pm 876$ & $5598 \pm 430$ & $7294 \pm 614$ & $11602 \pm 3378$ & \\
\hline Age (y) & $46.7 \pm 11.9$ & $46.0 \pm 11.9$ & $44.3 \pm 11.5$ & $42.7 \pm 11.3$ & $<0.001$ \\
\hline Men $(\%)$ & 42.1 & 42.1 & 42.1 & 42.1 & 1.000 \\
\hline BMI $\left(\mathrm{kg} / \mathrm{m}^{2}\right)$ & $25.6 \pm 4.8$ & $27.4 \pm 5.1$ & $28.0 \pm 4.8$ & $29.5 \pm 4.9$ & 0.032 \\
\hline Waist circumference $(\mathrm{cm})$ & $88.5 \pm 11.7$ & $90.3 \pm 11.7$ & $91.8 \pm 12.0$ & $93.5 \pm 12.1$ & 0.018 \\
\hline Body adiposity index (\%) & $30.5 \pm 6.0$ & $30.8 \pm 6.3$ & $30.4 \pm 6.1$ & $30.1 \pm 5.7$ & 0.250 \\
\hline Physical activity (Met-h/week) & 2003 & 2048 & 2170 & 2183 & 0.554 \\
\hline Current smoker $(\%)$ & 22 & 22 & 25 & 30 & 0.024 \\
\hline Educational status $(\%)$ & & & & & $<0.001$ \\
\hline Illiterate & 0.9 & 1.3 & 1.6 & 0.5 & \\
\hline Primary education & 68.8 & 68.7 & 60.2 & 62.7 & \\
\hline Academic education & 30.3 & 30.0 & 38.2 & 36.8 & \\
\hline \multicolumn{6}{|l|}{${ }^{1}$ Data are mean \pm SD } \\
\hline \multicolumn{6}{|c|}{ Table 2. Mean dietary intakes of participants by categories of dietary AGEs intake } \\
\hline \multicolumn{6}{|c|}{$\begin{array}{ll} & (\mathrm{n}=4080) \\
\end{array}$} \\
\hline & Q1 & $\mathrm{Q} 2$ & Q3 & Q4 & $\mathrm{p}$ \\
\hline & $\mathrm{n}=1019$ & $\mathrm{n}=1021$ & $\mathrm{n}=1021$ & $\mathrm{n}=1019$ & \\
\hline \multicolumn{6}{|l|}{ Dietary AGEs intake } \\
\hline Range & $<4832$ & $4832-6329$ & $6329-8466$ & $>8466$ & \\
\hline Mean & $3678 \pm 876$ & $5598 \pm 430$ & $7294 \pm 614$ & $11602 \pm 3378$ & \\
\hline Energy intake (kcal/d) & $1754 \pm 520$ & $2094 \pm 501$ & $2449 \pm 547$ & $2853 \pm 663$ & $<0.001$ \\
\hline Carbohydrate ( $\%$ of total energy) & $62.7 \pm 6.9$ & $60.2 \pm 5.8$ & $58.4 \pm 6.0$ & $55.3 \pm 5.9$ & $<0.001$ \\
\hline Fat ( $\%$ of total energy) & $26.2 \pm 5.7$ & $28.1 \pm 5.3$ & $30.1 \pm 5.5$ & $33.3 \pm 5.7$ & $<0.001$ \\
\hline Protein ( $\%$ of total energy) & $14.6 \pm 2.3$ & $14.9 \pm 2.4$ & $15.0 \pm 2.6$ & $15.6 \pm 2.7$ & $<0.001$ \\
\hline Total fiber $(\mathrm{g} / 1000 \mathrm{kcal})$ & $19.8 \pm 6.7$ & $19.1 \pm 5.9$ & $18.5 \pm 5.7$ & $17.3 \pm 5.6$ & $<0.001$ \\
\hline
\end{tabular}

Data are adjusted mean \pm SD

protein consumption of participants in the upper quartile of AGEs intake was higher than participants in the lower quartile of AGEs intake (26\% of total energy vs. 33\% of total energy, $\mathrm{p}<0.001$ and $14.6 \%$ of total energy vs. $15.6 \%$ of total energy, $\mathrm{p}<0.001$; respectively). There was a significant decrease in dietary intake of carbohydrate and fiber across the increasing trend of AGEs intake.

Table 3 shows the association between dietary AGEs intakes and anthropometric measures. There were significant associations between BMI, waist circumference and BAI and dietary AGEs intake in the crude model and after adjustment for possible confounding factors such as age, sex, physical activity, smoking status, education levels, and energy intake.

Odd ratio and 95\% confidence interval for general and abdominal obesity in each quartile category of AGEs intake are presented in Table 4.

The odds of general obesity in the second, third and fourth quartiles, compared to first quartile after adjustment for age and sex were 0.92 (95\% CI, 0.76 to 1.12$), 1.08$ (95\% CI, 0.89 to 1.31 ) and 1.24 (95\% CI, 1.03 to 1.50$)$, respectively ( $\mathrm{p}$ for trend $=0.015$ ); this significant finding disappeared after additional adjustment in models 3 and 4 . The odds of abdominal obesity had increasing trends across increasing categories of AGEs intake in model 3 (p for trend $=0.036$ ). Higher intake of AGEs increased the

Table 3. Association between dietary AGEs intakes and anthropometric measures $(\mathrm{n}=4080)$

\begin{tabular}{lccccc}
\hline Dietary AGEs intakes & Body mass index & $\mathrm{p}$ & Waist circumference & $\mathrm{p}$ & Body adiposity index \\
\hline Crude model & $0.12(0.03-0.21)$ & 0.062 & $0.13(0.05-0.21)$ & 0.035 & $0.18(0.09-0.27)$ \\
Adjusted model & $0.20(0.11-0.30)$ & 0.015 & $0.20(0.09-0.30)$ & 0.022 & $0.24(0.10-0.39)$ \\
\hline
\end{tabular}

Data are $\beta$ regression and $95 \%$ confidence interval estimated by using linear regression models with adjustment for age, sex, physical activity, smoking status, education status and energy intake.

Table 4. Odds ratio and 95\% confidence interval for general and abdominal obesity across quartiles dietary AGEs intakes ( $\mathrm{n}=4080)$

\begin{tabular}{|c|c|c|c|c|c|c|c|c|}
\hline Quartiles of AGEs intakes & \multicolumn{2}{|c|}{ Model 1} & \multicolumn{2}{|c|}{ Model 2} & \multicolumn{2}{|c|}{ Model 3} & \multicolumn{2}{|c|}{ Model 4} \\
\hline General obesity $(\mathrm{BMI} \geq 30 \mathrm{k}$ & OR & $95 \% \mathrm{CI}$ & OR & $95 \% \mathrm{CI}$ & OR & $95 \% \mathrm{CI}$ & OR & $95 \% \mathrm{CI}$ \\
\hline Q1 (<4799 kU, reference) & 1 & - & 1 & - & 1 & - & 1 & - \\
\hline Q2 (4799-6324 kU) & 0.89 & $\begin{array}{c}0.56 \text { to } \\
1.02\end{array}$ & 0.92 & 0.76 to 1.12 & 0.03 & $\begin{array}{c}0.83 \text { to } \\
1.28\end{array}$ & 0.02 & 0.92 to 1.41 \\
\hline Q3 (6324-8461 kU) & 0.98 & $\begin{array}{c}0.62 \text { to } \\
1.02\end{array}$ & 1.08 & 0.89 to 1.31 & 0.14 & $\begin{array}{c}0.93 \text { to } \\
1.42\end{array}$ & 0.06 & 0.86 to 1.34 \\
\hline Q4 (>8461 kU) & 1.08 & $\begin{array}{c}0.86 \text { to } \\
1.12\end{array}$ & 1.24 & 1.03 to 1.50 & 0.17 & $\begin{array}{c}0.96 \text { to } \\
1.46\end{array}$ & 0.13 & 0.70 to 1.17 \\
\hline$P$ for trend & & & & & & & & 01 \\
\hline
\end{tabular}




\begin{tabular}{|c|c|c|c|c|c|c|c|c|}
\hline \multicolumn{9}{|c|}{ Abdominal obesity $(\mathrm{WC} \geq 95 \mathrm{~cm})$} \\
\hline Q1 (<4799 kU, reference) & 1 & - & 1 & - & 1 & - & 1 & - \\
\hline Q2 (4799-6324 kU) & 0.98 & $\begin{array}{c}0.76 \text { to } \\
1.03\end{array}$ & 1.05 & 0.85 to 1.36 & 0.03 & $\begin{array}{c}0.83 \text { to } \\
1.27\end{array}$ & 1.36 & 1.06 to 1.93 \\
\hline Q3 (6324-8461 kU) & 1.15 & $\begin{array}{c}1.01 \text { to } \\
1.32\end{array}$ & 1.12 & $\begin{array}{c}-0.86 \text { to } \\
1.94\end{array}$ & 0.14 & $\begin{array}{c}0.93 \text { to } \\
1.41\end{array}$ & 1.42 & 1.06 to 2.32 \\
\hline Q4 (>8461 kU) & 1.14 & $\begin{array}{c}0.92 \text { to } \\
1.31\end{array}$ & 1.36 & $\begin{array}{c}-0.96 \text { to } \\
2.06\end{array}$ & 0.18 & $\begin{array}{c}0.97 \text { to } \\
1.47\end{array}$ & 1.56 & 1.16 to 2.84 \\
\hline $\mathrm{P}$ for trend & \multicolumn{2}{|c|}{0.425} & \multicolumn{2}{|r|}{0.257} & \multicolumn{2}{|c|}{0.036} & \multicolumn{2}{|r|}{0.032} \\
\hline
\end{tabular}

Model 1: Crude

Model 2: Logistic regression model with adjustment for age and sex.

Model 3: Additional adjustment for physical activity, smoking status and education status.

Model 4: Additional adjustment for energy intake.

odds of abdominal obesity by $56 \%(\mathrm{OR}=1.56,95 \% \mathrm{CI}$, 1.16 to 2.84$)$.

\section{Discussion}

Results of this study expand on the knowledge about the possible effects of consuming dietary AGEs on the human body. This study confirms that there is a relationship between dietary AGEs consumption and body adiposity in a way that with higher intake of dAGEs there is a significant increase in abdominal obesity. Moreover, this relationship remains significant after 2 models of adjustment for possible confounders. These results are in agreement with the findings of Hofmann et al. in mice when used two standard diets that were nutritionally equivalent and had different contents of dAGEs; they observed that despite their similar amount of food intakes, the mice on low-AGEs diet lost some weight. Nevertheless, they reported an increase in HDL levels in mice on low-AGEs diet, compared to mice on high-AGEs $\operatorname{diet}(25)$. Our finding also confirms the finding of a cross-sectional study done by Angoorani et al., who reported that higher intake of AGEs was associated with higher risk of abdominal obesity and hypertriglyceridemia; however, their result was not independent of dietary energy and macronutrient intakes(14). Although pathways via which consumption of dAGEs could lead to greater adiposity are not yet known, one explanation could be the harmful effect of dAGEs on insulin signaling and sensitivity in the body $(10$, 26) that contribute to higher levels of circulating insulin. One of the roles of insulin is to promote adipocyte triglyceride stores by a number of different mechanisms(27), and therefore can lead to greater fat storage and adiposity. AGEs have altering effects on extracellular function by two mechanisms: (1) formation of cross-links between key molecules in the basement membrane of extracellular matrix and (2) interaction of AGEs with the receptor for advanced glycation end products (RAGE) on cell surfaces (15). AGEs can also promote dyslipidemia. AGEs can form bonds with lipids as observed in samples from people with and without diabetes(28); glycated LDL then suppresses uptake and clearance of LDL through its receptor on endothelial cells $(15,29,30)$. It has also been postulated that high plasma levels of oxidative stress markers are positively correlated with elevated plasma triglycerides (31) and AGEs are known to increase oxidative stress in the body (15).

Another finding of this study is the relationship between consumption of dAGEs and a few anthropometric measurements. After adjustment for age, sex, physical activity, smoking status, educational status, and energy intake, a significant positive correlation was observed between BMI, WC, BAI and higher quartiles of dAGEs intake, with the correlation being stronger for BAI $(\mathrm{OR}=2.21)$. The BAI, which is based on the measurements of hip circumference and height, has been suggested as a new index of adiposity; it could be an appropriate tool to measure adiposity due, at least in part, to the advantages over other more complex mechanical or electrical systems but it appears that it cannot overcome BMI limitations for general use(32). However, a comprehensive study published in 2012 concluded that estimates of body fat percentage based on BAI were not more accurate than those based on BMI, waist circumference, or hip circumference(33). As for BMI, a study conducted in Italy supports the use of BMI as a fatness measure in groups of children and adolescents, although it warns that interpretation of findings should be cautiously done, when comparing BMI across groups that differ in age or when predicting a specific individual's total body fat (TBF) or percent of body fat (PBF)(34). Another study comparing the usefulness of $\mathrm{BMI}, \mathrm{WC}$, and waist to hip ratio (WHR) concluded that $\mathrm{BMI}$ and WC were found to perform well as diagnostic tests for fatness, whereas WHR was less useful(35). As stated, there are discrepancies as to whether or not a single anthropometric measure is a valid tool to estimate body fatness. Therefore, in this study, we have used three anthropometric measures, and they are all in agreement with higher dAGEs intake, more adiposity is observed.

As more studies explore AGEs and health status, more disturbing outcomes are reported. AGEs have been associated with numerous complications, namely increasing oxidative stress, diabetes, renal dysfunction, insulin resistance, cardiovascular disease and many more(10-13). Obesity and especially abdominal obesity, on the other hand, is the basis for many of the health complications in the world (36). Thus it is important for the public health sector to promote general knowledge and awareness about these components and encourage healthy meal choices and also avoiding preparation methods that contribute to higher AGEs content in foods.

The use of an FFQ that relies on the long term memory of subjects is one of the limitations of this study that can expose the outcome to memory biases and also limits food choices for individuals. As there is no AGEs content table 
for Iranian foods, we were forced to use the existing AGEs content table for American foods, and as there are certain Iranian food items that do not exist in that table, a few food items had to be removed and for some food items, estimateed amounts were used. Lastly, this study was limited by the use of cross-sectional data, and for that, these findings cannot be generalized to changes over time in this population.

Our large number of subjects is the main strength of this study, as is their present ability of our study population as people from all Iranian ethnic groups are known to live in the capital city of Tehran, which improves the generalizability of our findings. Furthermore, all data were collected by trained professionals and adjustments were considered for sex, age, energy intake, physical activity level, and smoking and education status to minimize the bias. The limitation of the present study is as follow. As we do not have a published food AGE database for Iranian food items, we had to apply the American published food-AGE database alternatively. Moreover, we had no accurate data on the methods of cooking which is strongly effective on the AGE contents of foods. In the present study, FFQ was used to calculate AGEs consumption over the previous year, but the likelihood of recall bias could not be ignored, which may result in misclassification of exposure.

\section{Conclusion}

Our research demonstrated that higher consumption of dietary Advanced Glycation End products in Iranian adults is associated with higher abdominal obesity, a relationship is independent of energy and macronutrient intake, which is also in agreement with the results of anthropometric measurements, such that higher quartiles of dAGEs intakes were found to be associated with greater BMI, WC, and BAI. These finding confirmed the results of another Iranian study which postulated that higher consumption of dAGEs was associated with higher risk of abdominal obesity. Our findings suggest that higher intakes of dAGEs may contribute to higher abdominal obesity.

\section{Acknowledgments}

We would like to thank the personnel of the Research Institute of Endocrine Sciences and TLGS participants. The authors wish to acknowledge Ms. N. Shiva for critical editing of English grammar and syntax of this manuscript.

\section{Conflict of Interests}

The authors declare that they have no competing interests.

\section{References}

1. James $\mathrm{W}$. The epidemiology of obesity: the size of the problem. J Intern Med. 2008;263(4):336-52.

2. Ford ES, Mokdad AH. Epidemiology of obesity in the Western Hemisphere. J Clin Endocrinol Metab. 2008;93(11_supplement_1):s1s8.

3. Organization WH. Cancer control: knowledge into action: WHO guide for effective programmes: World Health Organization; 2007.

4. Motlagh B, O'Donnell M, Yusuf S. Prevalence of cardiovascular risk factors in the Middle East: a systematic review. Eur J Cardiovasc Prev Rehabil. 2009;16(3):268-80.
5. Kelishadi R, Alikhani S, Delavari A, Alaedini F, Safaie A, Hojatzadeh E. Obesity and associated lifestyle behaviours in Iran: findings from the first national non-communicable disease risk factor surveillance survey. Public Health Nutr. 2008;11(03):246-51.

6. Semba RD, Nicklett EJ, Ferrucci L. Does accumulation of advanced glycation end products contribute to the aging phenotype? J Gerontol A Biol Sci Med Sci. 2010:glq074.

7. Uribarri J, Woodruff S, Goodman S, Cai W, Chen X, Pyzik R, et al. Advanced glycation end products in foods and a practical guide to their reduction in the diet. J Am Diet Assoc. 2010;110(6):911-6. e12.

8. Yan SD, Schmidt AM, Anderson GM, Zhang J, Brett J, Zou YS, et al. Enhanced cellular oxidant stress by the interaction of advanced glycation end products with their receptors/binding proteins. J Biol Chem. 1994;269(13):9889-97.

9. Sezavar H, Saboor-Yaraghi AA, Salehi E, Mottaghi A. Whether vitamin A supplementation is effective in T-bet and IFN- gene expression reduction? Immunol Invest. 2015;44(2):189-98.

10. Unoki H, Yamagishi S-i. Advanced glycation end products and insulin resistance. Curr Pharm Des. 2008;14(10):987-9.

11. Nin JW, Jorsal A, Ferreira I, Schalkwijk CG, Prins MH, Parving $\mathrm{HH}$, et al. Higher plasma levels of advanced glycation end products are associated with incident cardiovascular disease and all-cause mortality in Type 1 diabetes A 12-year follow-up study. Diabetes care. 2011;34(2):442-7.

12. Yan SF, Ramasamy R, Schmidt AM. Mechanisms of disease: advanced glycation end-products and their receptor in inflammation and diabetes complications. Nat Rev Endocrinol. 2008;4(5):285-93.

13. Goh SY, Cooper ME. The role of advanced glycation end products in progression and complications of diabetes. J Clin Endocrinol Metab. 2008;93(4):1143-52.

14. Angoorani P, Ejtahed H-S, Mirmiran P, Mirzaei S, Azizi F. Dietary consumption of advanced glycation end products and risk of metabolic syndrome. Int J Food Sci Nutr. 2016;67(2):170-6.

15. Goldin A, Beckman JA, Schmidt AM, Creager MA. Advanced glycation end products sparking the development of diabetic vascular injury. Circulation. 2006;114(6):597-605.

16. Baye E, Kiriakova V, Uribarri J, Moran LJ, de Courten B. Consumption of diets with low advanced glycation end products improves cardiometabolic parameters: meta-analysis of randomised controlled trials. Sci Rep. 2017;7.

17. Azizi F, Rahmani M, Emami H, Mirmiran P, Hajipour R, Madjid M, et al. Cardiovascular risk factors in an Iranian urban population: Tehran lipid and glucose study (phase 1). Soz Praventivmed. 2002;47(6):408-26

18. Hosseini Esfahani F, Asghari G, Mirmiran P, Azizi F. Reproducibility and relative validity of food group intake in a food frequency questionnaire developed for the Tehran Lipid and Glucose Study. J Epidemiol. 2010;20(2):150-8.

19. Goldberg T, Cai W, Peppa M, Dardaine V, Baliga BS, Uribarri J, et al. Advanced glycoxidation end products in commonly consumed foods. J Am Diet Assoc. 2004;104(8):1287-91.

20. Jiao L, Kramer JR, Chen L, Rugge M, Parente P, Verstovsek G, et al. Dietary consumption of meat, fat, animal products and advanced glycation end-products and the risk of Barrett's oesophagus. Aliment. Pharmacol. Ther.. 2013;38(7):817-24.

21. Kriska AM, Knowler WC, LaPorte RE, Drash AL, Wing RR, Blair $\mathrm{SN}$, et al. Development of questionnaire to examine relationship of physical activity and diabetes in Pima Indians. Diabetes care. 1990;13(4):401-11

22. Delshad M, Sarbazi N, Rezaei_Ghaleh N, Ghanbarian A, Azizi F. Reliability and validity of the Modifiable Activity Questionnaire (MAQ) in an Iranian urban adult population. Arch Iran Med. 2012;15(5):279.

23. Bergman RN, Stefanovski D, Buchanan TA, Sumner AE, Reynolds JC, Sebring NG, et al. A better index of body adiposity. Obesity. 2011;19(5):1083-9.

24. Azizi F, Hadaegh F, Khalili D, Esteghamati A, Hosseinpanah F, Delavari A, et al. Appropriate definition of metabolic syndrome among Iranian adults: report of the Iranian National Committee of Obesity. Arch Iran Med. 2010;13(5):426.

25. Hofmann SM, Dong HJ, Li Z, Cai W, Altomonte J, Thung SN, et al. Improved insulin sensitivity is associated with restricted intake of dietary glycoxidation products in the $\mathrm{db} / \mathrm{db}$ mouse. Diabetes. 2002;51(7):2082-9.

26. Uribarri J, Cai W, Peppa M, Goodman S, Ferrucci L, Striker G, et al. 
Circulating glycotoxins and dietary advanced glycation endproducts: two links to inflammatory response, oxidative stress, and aging. J Gerontol A Biol Sci Med Sci. 2007;62(4):427-33 .

27. Kahn BB, Flier JS. Obesity and insulin resistance. J Clin Invest. 2000;106(4):473-81.

28. Bucala R, Makita Z, Vega G, Grundy S, Koschinsky T, Cerami A, et al. Modification of low density lipoprotein by advanced glycation end products contributes to the dyslipidemia of diabetes and renal insufficiency. Proceedings of the National Academy of Sciences. 1994;91(20):9441-5.

29. Posch K, Simecek S, Wascher TC, Jürgens G, Baumgartner-Parzer S, Kostner GM, et al. Glycated low-density lipoprotein attenuates shear stress-induced nitric oxide synthesis by inhibition of shear stress-activated L-arginine uptake in endothelial cells. Diabetes. 1999;48(6):1331-7.

30. Gempel K, Gerbitz K, Olgemöller B, Schleicher E. In-vitro carboxymethylation of low density lipoprotein alters its metabolism via the high-affinity receptor. Horm Metab Res. 1993;25(5):250-2.

31. Marques de Mattos A, Marino LV, Ovidio PP, Jordão AA, Almeida CC, Chiarello PG. Protein oxidative stress and dyslipidemia in dialysis patients. Ther Apher Dial. 2012;16(1):68-74.

32. López AA, Cespedes ML, Vicente T, Tomas M, Bennasar-Veny M, Tauler $\mathrm{P}$, et al. Body adiposity index utilization in a Spanish Mediterranean population: comparison with the body mass index. PLoS ONE. 2012;7(4):e35281.

33. Freedman DS, Thornton JC, Pi-Sunyer FX, Heymsfield SB, Wang J, Pierson RN, et al. The body adiposity index (hip circumference: height1.5) is not a more accurate measure of adiposity than is BMI, waist circumference, or hip circumference. Obesity. 2012;20(12):2438-44.

34. Pietrobelli A, Faith MS, Allison DB, Gallagher D, Chiumello G, Heymsfield SB. Body mass index as a measure of adiposity among children and adolescents: a validation study. J. Pediatr.. 1998;132(2):204-10.

35. Neovius M, Linne Y, Rossner S. BMI, waist-circumference and waist-hip-ratio as diagnostic tests for fatness in adolescents. Int $\mathrm{J}$ Obes. 2005;29(2):163-9.

36. Mottaghi A, Mirmiran P, Delshad H, Azizi F. Effect of Different Obesity Phenotypes on Incidence of Chronic Kidney Disease in Tehranian Adults. J Am Coll Nutr. 2016;35(7):587-96. 